\title{
STUDENTS' COMPREHENSION OF DESIGN COLLABORATIONS WITH EXTERNAL ORGANIZATIONS
}

\author{
Gottlieb, Laura; Eriksson, Yvonne \\ Mälardalen University
}

\begin{abstract}
This pilot study examines how design students comprehend collaborations with external organizationsthe roles and involvement of different actors in a design process. The study looks at two undergraduate courses where a total of 33 design students collaborate with a municipality and governmental agency. Data focuses on the students' terminology in regard to the external organizations and is collected through questionnaires, voice recording, workshops and written assignments. The data analysis is both quantitative and qualitative, focusing on the word frequency and semantics of the terminology. The results show that the students were not used to working closely to external organizations. This is reflected in the prevalent use of the term "client" instead of "collaborative partner". Not working closely with organizations nor users is reflected in the students' inabilities to handle the complexities that emerge when working with multiple stakeholder and users. At the end of the paper, suggestions are made of ways to develop students' comprehension of ways to involve external organizations and users in the design process.
\end{abstract}

Keywords: Design education, Design process, User centred design

\section{Contact:}

Gottlieb, Laura

Mälardalen University

Information Design

Sweden

laura.gottlieb@mdh.se

Cite this article: Gottlieb, L., Eriksson, Y. (2019) 'Students' Comprehension of Design Collaborations with External Organizations', in Proceedings of the 22nd International Conference on Engineering Design (ICED19), Delft, The Netherlands, 5-8 August 2019. DOI:10.1017/dsi.2019.62 


\section{INTRODUCTION}

In the 1970s several new university colleges were founded in Sweden. The aim of these university colleges was to spread access to higher education in areas were a large part of the population lacked a higher education. This government initiative was highly supported by the regions, local authorities and by companies that needed educated employees, especially engineers. In many ways the founding of the university colleges in the 1970s could be described as a collaboration process between various actors: the regions, municipalities, politicians and companies. Several of the university colleges developed later into universities with high ranked research and post-graduate education. Influenced by the requirement on universities to have an impact on society, the new universities started to profile themselves as universities that conduct research and education in collaboration with society (Bölling and Eriksson 2016). This has led to a discussion about how to define these kinds of collaborations and what terminology to use. Collaboration, co-creation and co-production are some terms used to denote collaborations between university and external partners. In this study, we follow a university in Sweden which has collaboration with society as a core strategy. In this university, students are expected to have both practical and theoretical knowledge of collaborating with society upon graduating. The purpose for this is to prepare students for the increased rate of change in society and to handle and drive change processes.

Design education programs frequently collaborate with external organizations to contribute to new and relevant solutions for existing problems. One of the expected learning outcomes from courses in collaboration with external organizations should be the ability to collaborate in projects with various stakeholders and users. However, from students' written assignments and presentations we have identified a limitation in relation to comprehension of what it means to identify users' needs and especially how to involve users and stakeholders in the design process. These skills are regarded as crucial for future designers according to the Swedish Association for Industrial Design (Isaksson 2017). Despite strategical decisions from the university management regarding collaboration as flagship and the overall target for the university's design education, it is not always anchored among the teachers and the students. In order to develop skills among students regarding collaboration, we conducted a pilot study as a first step to gain knowledge about how students comprehend collaboration with external organizations. Comprehension here means how students perceive the roles and involvement of different actors, including themselves. The research question of this study is: How do students comprehend the collaboration with the external organizations and their own role in the collaboration?

\section{PREVIOUS RESEARCH}

Collaborating with external organizations is important for students in order to develop broader competences of collaborating with people from other fields and cultures (Eriksson 2016). Methods for collaborating between students and external organizations are described in the following studies (Robben et al., 2012, Falk-Kessler et al., 2007, Vilkki and Luojus 2013, Dabaieh et al., 2018, Fan et al., 2014, Jäminki and Saranne 2013, Evans et al., 2013). These studies describe various ways of structuring collaborations in education, such as students being involved in segments of real research projects (Jäminki and Saranne 2013) or sharing work spaces with businesses (Fan et al., 2013). The studies delineate benefits and challenges, as well as important conditions for such collaborations. This includes the necessity for students to have training and guidance in research methods involving users (before and during participation) and to have regular meetings with stakeholders (Robben et al., 2012). A challenge in these collaborations can be to combine the time frames of the courses or school semesters with external actors and real-life projects. The starting point for finding previous research was to look at studies conducted within Living Labs as these focus on incorporating education in reallife environments and the involvement of users. We did not limit this search to design education as to broaden our perspectives on types of collaborations between students and external organizations in various disciplines. Participatory design is the central approach advocated in Living labs which are "aimed at co-creating innovation through the involvement of aware users in a real-life setting" (Dell'Era and Landoni 2014). The participatory approach moves away from an expert-lead process towards creative involvement of many different people. This involves a mindset that all people are creative and experts of their own experience (Sander 2013). Involving users throughout the whole process means letting go of the control of a specific outcome, product or service. It differs from a user- 
centred approach, as it is not about testing ideas in later stages of the design process. This shift implies a change in power relations between designers and users (Sanders and Stappers 2008) and a change in terminology. The passive user becomes an active partner in the participatory relationship (Sanders 2013). Sanders and Stappers discuss that "future co-designing will be a close collaboration between all the stakeholders in the design development process together with a variety of professionals having hybrid design/research skills" (2008:16). The above literature about student collaborations with society outlines ways of collaborating with different stakeholders and users. They place emphasize on developing a proficiency in research methods for involving users and that this requires a certain mindset. None of the articles that we have found have focused on student' comprehension of collaborations. We see that it is an important aspect to study, to understand how processes influence student' comprehension of collaborations and of their roles as designers in different types of collaborations.

\section{PILOT STUDY}

\subsection{Background}

To examine student' comprehension of collaborations with external organizations, a pilot study was conducted. The pilot study included two undergraduate courses with a total of 33 information design students. Course 1 included third-year students and lasted for 5 weeks between December 2017 and January 2018. Course 2 was with second-year students for a duration of 10 weeks between March and May 2018. In the courses, students received a brief from a municipality and government agency in relation to an urban development project. The brief was developed by the teachers, researchers and representatives from the municipality and government agency. The urban development project involved building new workspaces for the agency and invigorating a city area. An intention in the courses was to introduce the students to the concept of a collaborative partner. The teachers and researchers presented the municipality and agency as collaborative partners at the start of the course and this was also written in the course syllabus. The collaboration between the university, municipality and government agency was part of a larger initiative to develop a long-term collaboration.

\subsection{Student project}

The students' task in the courses was to create design proposals for a specific road connecting the railway station and the government agency's new building. The intended users in the project were visitors and employees of the agency as well as the local community. The overall aim of the connecting road was to highlight the presence of the agency in the town. Representatives from the municipality and agency met with students in the beginning of the course to introduce the urban development project and the brief. During the course, students visited the organizations and lectures were provided by staff from the organizations with specific competences, such as landscape architecture. At the end of the project students presented the design proposals to the organizations. In course 1, presentations were in the form of 3 minute "pitches" to the employees at both of the organizations. The students also exhibited their project portfolio in the offices of the municipality and government agency. In course 2, representatives from the organizations came to the university and each student received 15 minutes to present and discuss their proposal.

\subsection{Data collection}

Data collection focused on the students' experiences of working with external organizations in the courses. This included asking students about methods, forms of communication, tensions, roles, contributions and terminology that related to the external organizations. Data was collected during four stages in each course through questionnaires, voice recording, written assignment and workshops. The purpose for this was to see how students comprehend the collaboration before, during and after the course, and whether any changes occurred. The number of students participating in different stages varied as attendance in the course workshops and lectures was not compulsory. Although this meant having fewer respondents in some stages, it was beneficial to have in-depth discussions with smaller groups of students. Table 1 shows when each stage occurred, which data collection methods were used and how many students participated. 
Table 1. Participants, methods and time of data collection

\begin{tabular}{|l|l|c|r|}
\hline Stage & Period & $\begin{array}{r}\text { Methods of data } \\
\text { collection }\end{array}$ & $\begin{array}{r}\text { Number of } \\
\text { participants }\end{array}$ \\
\hline 1 & $\begin{array}{l}\text { Beginning: 1st week of } \\
\text { course }\end{array}$ & Questionnaire & 16 (course 1) \\
17 (course 2)
\end{tabular}

Questionnaires were used in stages 1-3 to collect the students' experiences of working with external organizations in the courses. In stage 3 , the questionnaires were filled out in smaller groups to provide a starting point for a class discussion. In this case, the discussions were recorded (96 minutes in total) and transcribed. A workshop was held in each course to have detailed discussions with students about their design processes and how these involved the external organizations. Visual and creative techniques were used to elicit deeper reflections and to encourage sharing amongst participants (Sanders 2013, Sanders and Stappers 2013). The workshops were 1.5 hours (course 1) and 2 hours (course 2) long. In course 1, participants in the workshop made collages to visualize their processes (see figure 3 in results). The students visualised different aspects of their process (stakeholders, aims, feelings, insights, methods) with different colours. The purpose for asking students to create collages was to get a deeper understanding of how they perceive the process, and to highlight the relationships between methods, stakeholders and outcomes (Arnheim 1969, Gauntlett 2007). The workshop was structured after Gibbs' model of reflection (1988) which breaks up the reflective process into different stages. The collages were made individually and then discussed in smaller groups. The workshop with students in course 2 had a different format than in the course 1 . In the course 2 workshop participants engaged in a writing exercise to reflect on and discuss the meaning of co-creation. Co-creation was chosen as the topic in order to explicitly discuss close collaborations with external organizations and the students' experiences of such processes. During this writing exercise, each student wrote down a list of words that they associate with the word co-creation and then elaborated on the meanings of these words. These words were then discussed in relation to previous experiences of working with external organizations. A card sorting technique was also used during this workshop to map out the students' design processes (Gottlieb 2017). A specially designed card deck was used containing four different categories: stakeholders, project aims, processes, and outcomes. Each card contained an example from one of the categories, for instance, "public institution" was a stakeholder card. In groups of two or three, students sorted and arranged the cards in order to plan their processes (see figure 2 in results). The final stage of data collection included written assignments that students from both courses submitted at the end of the course. The purpose of the written assignment was for students to summarize and reflect upon their process and results. A total of 15 essays were received.

\subsection{Data analysis}

The analysis focused on the words that students used to refer to the external organizations and collaborations. Both quantitative and qualitative methods for data analysis were used to see the frequencies of these words as well as their meanings. The way that the data was collected and analysed varied between the courses as themes emerged throughout the process. For example, students in course 1 were involved in analysing parts of their data from previous questionnaires. This allowed participants to clarify and expand on the data. This was not done in course 2 as by this time questions were more directed to the emerging themes in the study, such as the distinction between words like client and collaborative partner. At the end of the data collection, a word frequency analysis was conducted to indicate whether there was a certain kind of discourse (Hansen 1995). The word frequency analysis distinguished between the stage and course in which the words were used and whether the words were 
used in relation to a researcher's question. The purpose for this was to see the influence of the researchers on the words that the students used. Keywords were selected on the basis of words in the data that refer to the organizations and to collaborative processes. The keywords for the analysis were: client, target group, co-creator, collaborative partner, stakeholder, co-creation, collaboration, and cooperation. For the purpose of this paper, the keywords and selected extracts from the data have been translated from Swedish. The qualitative analysis was conducted to elicit what meanings students attribute to these terms. Each keyword was categorized, and the data was coded and sorted in the categories. From this categorization further themes emerged, such as: expectations on the organizations, dealing with ambiguities, client vs. partner, user methods. The data in the results section is referenced in relation to the course and the stage number. For example, C1.2 means that the data comes from course 1 , stage 2 .

\section{RESULTS}

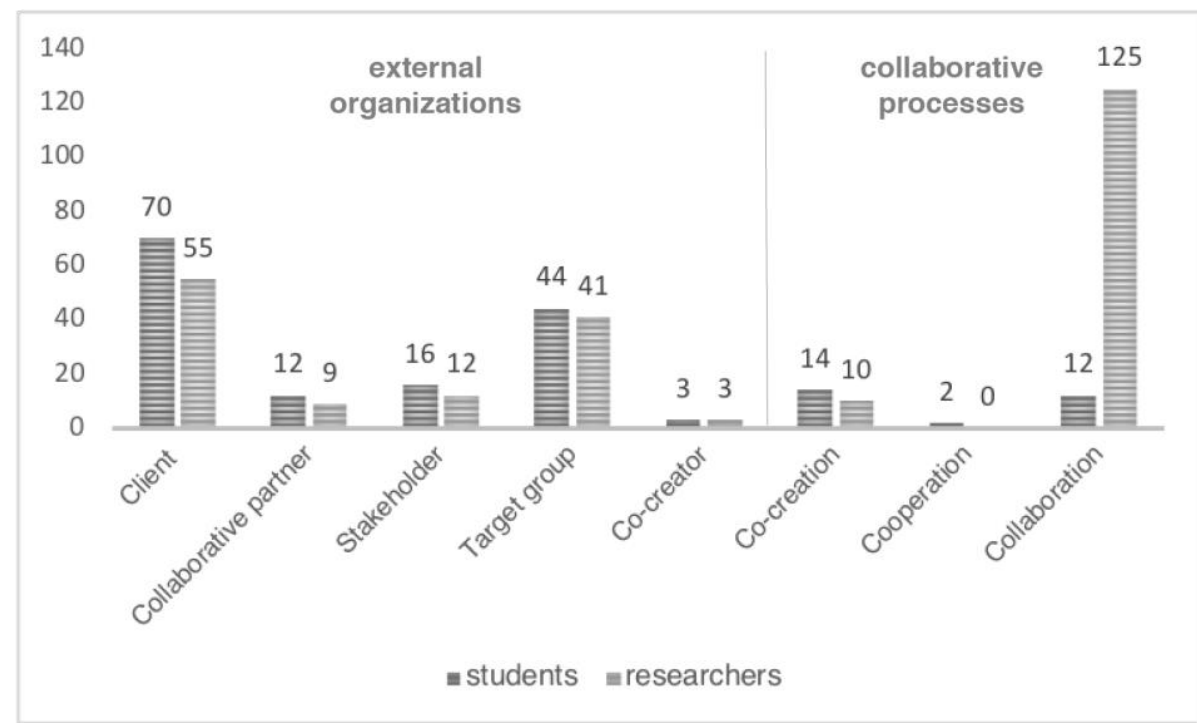

Figure 1. The total amount of times students and researchers used the terms in the four stages of data collection

\subsection{Client vs. Partner}

Client was the most commonly used word in the two courses to describe the organizations (70 times). Upon defining the words client and collaborative partner, all students agreed that client was the most appropriate word to describe the organizations. Students understood client as someone who pays for the project, that gives the brief and that is "some kind of a decision-maker" (C1.3, C2.3). Students used the term collaborative partner 12 times, of which only three of these occasions were not in relation to a researcher's questions $(\mathrm{C} 1.1, \mathrm{C} 2.4)$. Students defined a collaborative partner as someone who "has the same client but different competences", "that works together" and "has more input in the work" (C1.3). Students were aware of the intention for the external organizations to be collaborative partners in the course, however, they thought that the organizations "have been more like clients" (C2.3). According to students there was no partnership due to a lack of dialogue, an "us-them feeling" and because "[the students'] gave more than [they] got" (C2.3). In one instance a group of three students said that organizations could be seen as partners as they came with input in the form of "lectures and... knowledge" (C2.3). However, the students then said that "there was not much of it" and they wanted more critical feedback and relevant lectures (Ibid.). They suggested having more communication during the process, for example in forms of tutorials (C2.3) or a joint workshop with all stakeholders (C1.3). The term co-creation was a new concept for students in course 2 (C2.2). Their experiences of co-creation were in relation to other students rather than external organizations.

\subsection{Ambiguities and expectations}

Students said that it was "confusing in the beginning to have two stakeholders/clients" (C1.2) and "two different people to satisfy" (C1.3). They expressed that the organizations should provide clearer 
instructions and to "talk a bit [amongst themselves] before they present [the brief] to the [students]" $(\mathrm{C} 1.3, \mathrm{C} 2.3)$. Students said that they need to "demand clarity" from the organizations and to ask more questions at the start (C1.3). A group of four students suggested holding a workshop with all stakeholders to resolve ambiguities (C1.3). The ambiguities were that the municipality's aim was to invigorate a city area, whereas the agency's focus was on their new office building. Furthermore, the organizations had different target groups (citizens and employees) which remained unspecified. A student said that "the problem in the project needs to be clear and seen in the same way. This is why communication is important" (C1.3). Students were also confused about how to combine the expected learning outcomes in the course with the organizations' vision for the project. Students in course 1 expressed being tired towards the end of the semester and frustration over the unclear brief (C1.2). Although students claimed that they wanted a more defined brief, they also said that they can be flexible in regard to the organizations' wishes (C1.2). A group of four students discussed: "these [desires and expectations] are not really something we have to relate to, because if we can find a better solution we just have to show and explain to the client that these expectations are not realistic, but that we have this solution instead" (C1.3). In relation to this discussion, a student expressed that organization sometimes "want to interfere in the design" and "don't trust that [the students] have the knowledge to design" (C1.3).

\subsection{User needs}

The users' and stakeholders' needs and desires played an important role in the students' descriptions of their projects. Students expressed a wish to engage in dialogue with "people in the area... and the employees of the government agency" in order to get a deeper understanding of their needs and desires (C2.4). Students from both courses suggested using interviews, workshops, focus groups and questionnaires to engage with the users $(\mathrm{C} 1.4, \mathrm{C} 2.4)$. The students claimed that they contribute to the organizations by "satisfying [the organizations'] visions" (C1.3). They wanted the organizations to be more involved throughout the design process by providing tutorials, in order "to achieve better results where all parties are satisfied" (C2.4). However, students in course 1 acknowledged that this may not be possible as the organizations are busy (C1.3). A group of three students discussed that their design proposals "centre on the human and comfort in the designed spaces" $(\mathrm{C} 2.3)$.

\subsection{Involving users}

Students did not work with methods which directly involve the users, in this case the employees and visitors of the government agency and the local community. Instead, they used methods such as observations and mapping. The lack of methods involving users is something students said was a weakness in their processes $(1.3,2.4)$. Not working directly with users was common in other courses in the design program. A second-year student reflected on "how little [the students] have worked in courses with methods directly involving users" (C2.2). The visual outcomes from the workshop with second-year students indicate a separation between methods and stakeholders in a project. Students in this workshop were planning and mapping out their processes using a specially designed card deck. The cards represented different categories: stakeholders, project aims, processes, and outcomes. In groups of two or three, students picked cards that were appropriate for describing their projects. The students then arranged the cards to demonstrate their process. Although only two groups (with a total of 5 students) did this exercise, both groups separated the stakeholder and the process cards (see figure 2). The stakeholder cards are marked with black circles and the process cards are marked with white circles. The cards representing the external organizations were placed at the left side of the visualization, at the start of the project, while the process cards were placed on the right side, towards the end of the project. Only the stakeholder cards representing citizens and university were placed in direct relations with methods on the right side. The collage exercise in course 1 also shows a separation between methods and stakeholders (see figure 3). Only the university stakeholder is positioned in close proximity to a method in the collage in picture A in figure 3. A student said that using different colours in the collage made her process look messier than it was (C1.2). The visual outcomes in course 1 were descriptive of the collaboration rather than in course 2 where the visualizations were prescriptive. This is because students in course 1 were further along in their process when doing this workshop. 


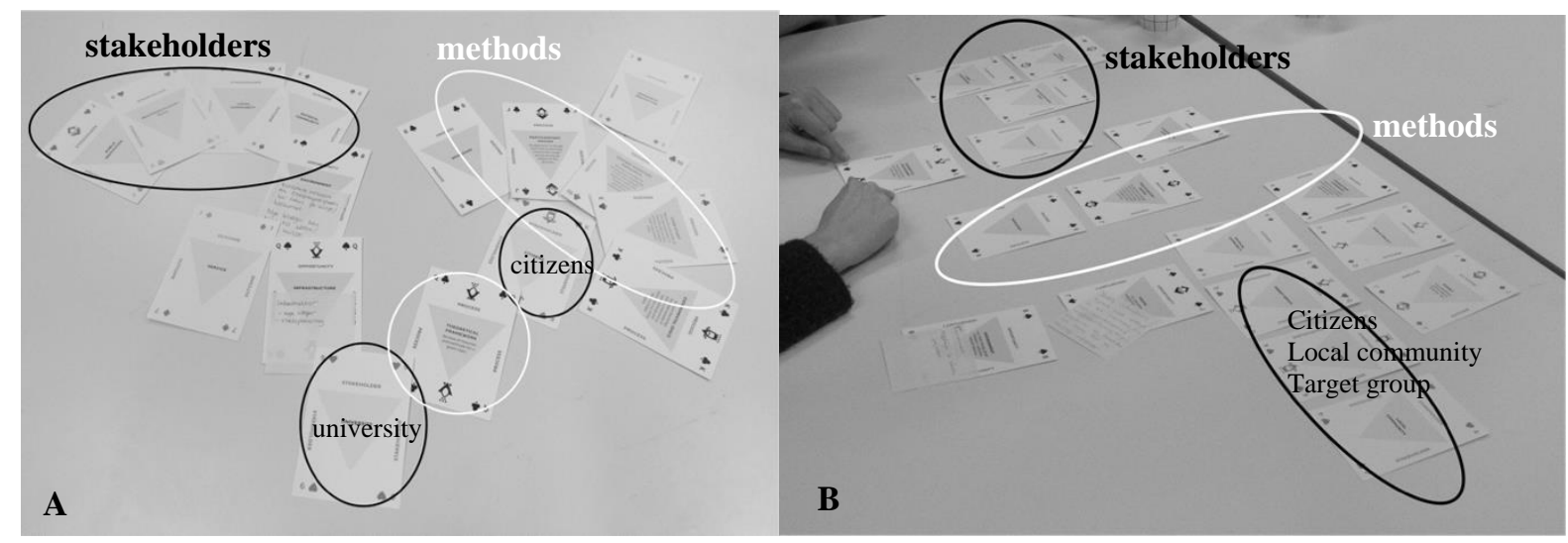

Figure 2. Cards used in course 2 to visualize student processes. The categories of cards are: stakeholders, processes, outcomes, and aims

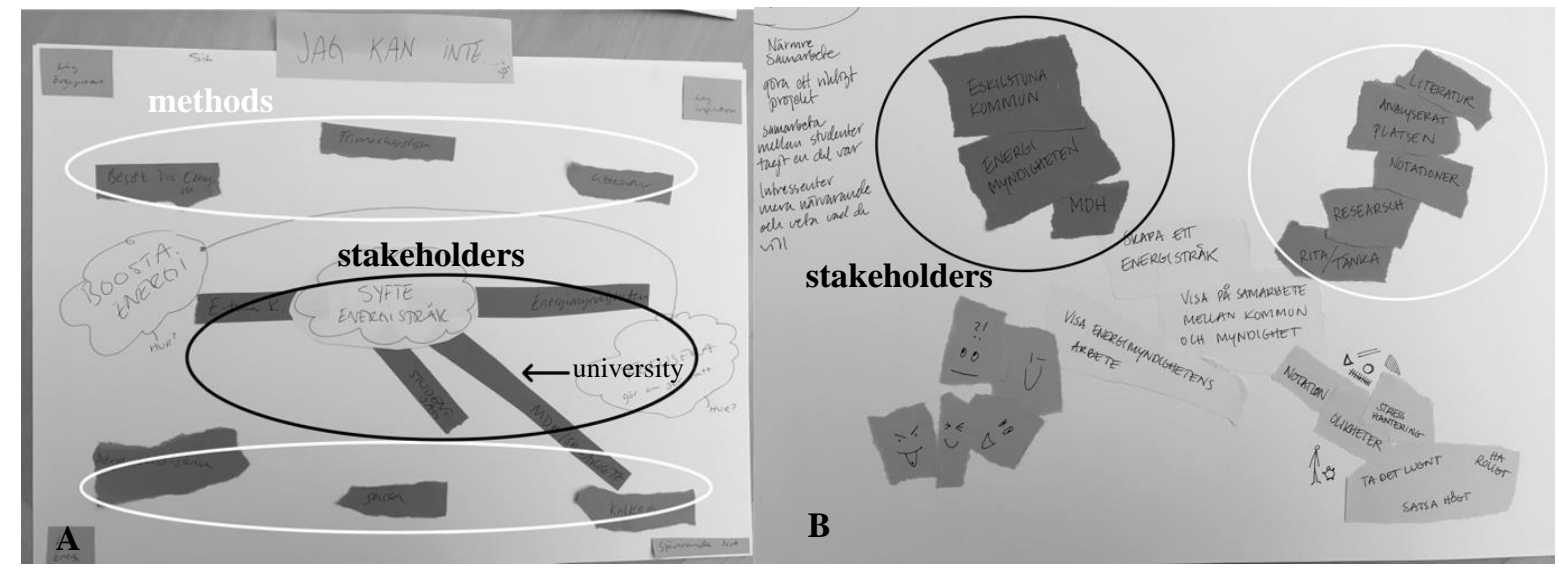

Figure 3. Collages from the course 1 workshop. The different categories are: stakeholders, project aims, methods, feelings, insights

Moreover, the expected learning outcomes in the course syllabuses related to using methods for analysing spaces instead of methods for user involvement. This is reflected in the focus of the lectures as well. One out of six expected learning outcomes related to the ethical deliberations concerning users.

\subsection{Opportunities to interact with users}

There were two occasions when students were given the opportunity to interact with users and chose not to. In course 1, students wanted to send out questionnaires to the employees of the government agency. Instead, staff from the agency offered students the possibility to ask the questions in person to employees in the lobby. The students rejected this proposal saying that "it doesn't feel like a solution... to grab people" (C1.3). In course 2, a local resident told two students during their street observations about the discontent of local residents in regard to the municipality's building plans for the connecting road in the students' brief. The class was invited to attend a local meeting about this issue, but the students did not follow up on this. None of the students discussed this in their project outcomes - the design proposals, presentations, and written assignments. A student said that this was not relevant as "[the housing estate] was not the exact place that [the student] was working on" (C2.3). The housing estate was on the same connecting road that the students were working on.

\section{DIscussion}

\subsection{Terminology}

The words that the researchers used influenced the students' terminology in the data collection. The students used the words co-creation $(\mathrm{C} 2.2)$ and stakeholder $(\mathrm{C} 1.2)$ in the workshops when the researchers used these words. This is what lead to the study's focus on the terminology as students used the term client without prior mention of this word by the researchers. This pointed to a certain terminology used in other courses that may be introduced by the teachers. Hence this study questioned 
what terminology students use and how it is understood. According to the students, client was most appropriate to use to denote the organizations due to the limited interactions in the courses and existing power relations where organizations are decision-makers. This indicates that terminology relates to collaborative processes and roles. In order to call the organizations collaborative partners, students said that more dialogic processes and input in the design process is needed. However, we also see that students did use collaborative partner to refer to the organizations in the written assignments and questionnaires. This is likely to have been influenced by the researchers and teacher that introduced the organizations as partners at the start of the courses. On the other hand, upon further discussion students did not think there was enough involvement for it to be a partnership. This again indicates the close tie between terminology and processes.

In Participatory Design there is a significant link between terminology and mindset. Using the term partner rather than user implies a certain way of understanding people as creative and having a larger role throughout the design process. During the study, students expressed that organizations sometimes want to interfere in their designs. This raises questions in regard to how students see the role of other stakeholders in the creative stages of the design process. Rejecting the organizations' input into the design can be interpreted as a contrary approach to that of a co-designer, where multiple people are involved in developing the design. Although the students are "experts" in the information design domain, it is important to acknowledge what expertise their collaborators have that is important for the design outcome.

\subsection{Dealing with ambiguities}

Students claimed that the organizations and teachers should resolve ambiguities first, and once this is done, present a clear brief and unified vision for the project. Only one group of four students suggested that students could be involved in resolving ambiguities through a workshop with all stakeholders. This indicates that students did not perceive their role as being involved in resolving ambiguities with the organizations. One reason for this could be the limited interaction that students had with organizations during the courses. The courses were only 5 and 10 weeks long and students acknowledged that the organizations had limited time to participate in the projects. This could have contributed to why students did not think it was possible to have discussions concerned with resolving ambiguities. The short time frame of the course could contribute to the frustration that students expressed in relation to the ambiguities. That was particularly so in course 1 which was only 5 weeks long and towards the end of the semester. The short time span of courses and school semesters (up to 20 weeks) are not suitable in terms of engaging with real-life design processes (Robben et al., 2012). A suggestion for dealing with time issues is to involve students in only a segment of a real research project (Jäminki and Saranne 2013). The final design proposal is then not of concern, but focus is placed on working with a specific method with users and collecting data which feeds into the research project. We see that it is important for students to learn to understand their role as designers as being involved in resolving ambiguities together with stakeholders and users.

\subsection{User involvement}

The students did not problematize the involvement of multiple users and stakeholders in the design process. Students wanted to involve multiple users but did not acknowledge the conflicts that can arise. This is particularly clear in course 2 when students became aware of a disagreement between the local residents and the municipality. The students did not follow up on the invitation to attend a local meeting about this issue. Nor did any students raise this issue in their design deliberations and results. A student said that it was not relevant for their design proposal as the housing estate was a few meters down the road. This points a lack of acknowledgement and ability to handle complexities involved in working with multiple stakeholders and users. Furthermore, the rejection of engaging with users could be interpreted as an uncertainty as to how to interact directly with users. This could explain why students in course 1 rejected the opportunity to interview employees in the lobby of the agency's building. The students wanted to send questionnaires instead of approaching employees. We see that it is important for students to experience direct involvement of users and to understand the complexities involved in working with multiple actors. This would need to include deliberations about the power relation between different users and stakeholders and the students' roles in relating to these. In course 2 for instance, students were concerned with the municipality's needs rather than the local residents' 
needs. Students should articulate why different groups are involved and the students' role in lifting certain perspectives.

The lack of involving users points to a discrepancy between what the students say and what they do. Students say that their designs are for users, but eliciting user needs is not reflected in their methods. The visual methods used in the workshops in course 1 and 2 reflect a separation in the methods and stakeholders/users. When planning or describing their processes, students kept the organizations on one side of the visualization, at the start of the project, and the methods on the other side (figures 2 and 3). However, this may also be influenced by other factors such as wanting to make tidy, color-coded collages. The research on collaborations between students and external organizations emphasize the need to train and guide students in user methods, before and during interactions with users, as well as interacting with stakeholders regularly (Robben et al., 2012). We also recognize these as important factors in developing collaborations between students and external parties. The courses therefore need a larger focus on dialogic with stakeholders and supporting students in involving users. This should also be made explicit in the expected learning outcomes and course syllabus.

\section{SUGGESTIONS}

The following are suggestions for developing collaborations between students and external organizations:

- Make user methods and stakeholder interaction a central focus in the course and define these as expected learning outcomes

- Train and guide students in these methods before and during user and/or stakeholder interactions

- Focus on a particular user method and engagement rather than an outcome

- Problematize user involvement (or lack of) with students: Whose/what perspectives need to be considered? What methods are appropriate?

\section{CONCLUSION}

This study was conducted to better understand current forms of design collaborations between students and external organizations and how students comprehend these collaborations. The purpose was to understand how to develop ways in which students collaborate with diverse users and stakeholders and how they reflect about these processes. As predicted, design students at the university in this pilot study are used to collaborations structured around the organization delivering a brief and students presenting design outcomes. We learnt that students were not experienced in working with methods directly involving users or working closely with organizations. This is reflected in the students' prevalent use of the term client rather than collaborative partner. The study shows that this format for collaboration has certain implications on the students' comprehension of their roles in the collaboration. One such implication is that students did not perceive their own role in resolving ambiguities together with the stakeholders. Instead students thought that the organizations need to come with clear briefs and to resolve any ambiguities amongst each other. We see that students need to be involved in these negotiations and problem definitions in order to learn how to handle complexities that arise when working with several actors. Another implication is that students did not show abilities to problematize the involvement of multiple actors in a design project. This was particularly clear in course 2 when students did not deliberate on a conflict that arose between the local residents and the municipality. The lack of user involvement points to a discrepancy between what the students did and said. Whereas they describe their design process as being towards users' needs this is not reflected in the methods. We see this as an important next step in the development of design education. Students should be trained and experience direct involvement with users and stakeholders in their methods and to develop critical perspectives around this: whose desires/needs are raised and prioritized? How are different users involved? It is important to train future designers to work in complex design processes that are not limited to clear briefs and outcomes. A difficulty in involving stakeholders and users in student courses is the limited time frames for the course projects. A suggestion from the literature is to focus on a specific participatory method rather than an outcome.

A limitation of this study is that the final results were not discussed with students. In future studies, it would be useful to discuss the results with the students in order to iterate on the findings. Furthermore, this paper does not mean to suggest that all students comprehend collaboration in the same way. The purpose was to gage what perspectives exist amongst students in order to develop approaches in 
education for collaborations with external partners. From this we can see a need for more dialogic structures and for students to learn to handle complexities which arise when working with multiple actors in a design process. We see that this requires a certain mindset where students are inclined to deal with ambiguities together with stakeholders and users, and to involve others in the design process.

\section{REFERENCES}

Arnheim, R. (1969), Visual Thinking. University of California Press, Berkeley

Bölling, M. and Eriksson, Y. (2016), "Collaboration with society: The future role of universities? Identifying challenges for evaluation", in Research Evaluation, Vol. 25 No. 2, 2016, pp. 209-218, http://doi.dx.org/10.1093/reseval/rvv043

Dabaieh, M., El Mahdy, D. and Maguid, D. (2018), "Living Labs As a Pedagogical Teaching Tool for Green Building Design and Construction in Hot Arid Regions", in International Journal of Architectural Research, Vol. 12-1, pp. 338-355

Dell'Era, C. and Landoni, P. (2014), "Living Lab: A Methodology between User-Centred Design and Participatory Design", in Creativity and Innovation Management, Vol. 23 No. 2, pp. 137-154. http://doi.dx.org/10.1111/caim.12061

Eriksson, Y. (2016), "Interdisciplinary learning: meeting future challenges", chapter in Eds. Vacca, F., Warshavski, T. (2016), Interdisciplinary Research and Education Agenda, Florence, Mandragora

Evans, J., Jones, R., Karvonen, A., Millard, L. and Wendler, J (2015), "Living labs and co-production: University campuses as platforms for sustainability science" in Current Opinion in Environmental Sustainability 2015, Vol. 16 No. 1-6

Falk-Kessler, J., Benson, J.D. and Witchger Hansen, A. (2007), "Moving the Classroom to the Clinic: The Experiences of Occupational Therapy Students During a 'Living Lab"', in Occupational Therapy in Health Care, Vol. 21 No. 3, pp. 79-91, http://doi.dx.org/10.1080/J003v21n03_05

Fan, F., Tang, T., Nyberg, T. and Hämäläinen, M. (2014), "Using Living Labs Methodology to Design Entrepreneurship Education Program in China: The case of a Pilot Minor at Tongji University in collaboration with Aalto University", in proceedings ENoLL Living Lab Days, Amsterdam 2-5th September

Gauntlett, D. (2007), Creative explorations. Routledge, New York.

Gibbs, G. (1988), Learning by Doing: A guide to teaching and learning methods. Further Education Unit, Oxford Polytechnic, Oxford.

Gottlieb, L. (2017), "The Knowledge Triangle Cards: supporting university-society collaborations", in proceedings for 11 th European Conference for Game-Based Learning, Graz 5-6th October

Hansen, A. (1995), "Using information technology to analyze newspaper content", in R.M. Lee (ed.), Information technology for the social scientist. UCL Press, London

Isaksson, D. (2017), Darjas drivkraft är data och design. Swedish Industrial Design Foundation website, viewed on 7 April 2018, <http://svid.se/sv/Forskning/Design-Research-Journal/Las-och-ladda-ner-DesignResearch-Journal/Nr-1-2017/Darjas-drivkraft-ar-data-och-design/>

Jäminki, S. and Saranne, M. (2013), "Living Labland" - Co-creative Innovation Lab Integrating Cross-border Co- creation of services to research, development and innovation in Higher Education", in proceedings 4th European Network of Living Labs Summer School, Manchester, August 27th

Robben, S., Kanis, M., Kröse, B. J. A. and Veenstra, M. (2012), "Living Labs as Educational Tool for Ambient Intelligence", In Ambient Intelligence: Third International Joint Conference, AmI 2012, Vol. 7683 (Lecture Notes in Computer Science). Springer Verlag, Pisa.

Sanders, E.B. and Stappers P.J. (2008), "Co-creation and the new landscapes of design", in Co-Design, Vol. 4 No. 1, pp. 5-18, http://doi.dx.org/10.1080/15710880701875068

Sanders, E.B. and Stappers, P.J. (2013), Convivial Toolbox: Generative Research for the Front End of Design. BIS Publishers, Amsterdam

Sanders, E.B. (2013), "Perspective in Participation in Design", in Wergestalter die Gestaltung, pp. 61-74

Vilkki, O. and Luojus, S. (2013), "Living Lab Activities as the Starting Point for Developing ICT Studies in Higher Education", in The International HETL Review, Special Issue, 2013, pp. 14-32

\section{ACKNOWLEDGMENTS}

We are grateful to the students and teachers that participated in this study. We would also like to extend our gratitude to Chris Gottlieb and Jennie Andersson Schaeffer for their valuable feedback on this paper. 